\title{
ITF

\section{Plantar pressures in simulated tennis movements at different surfaces}

\author{
Christos Mourtzios (GRE)
}

ITF Coaching and Sport Science Review 2017; 71 (25): 19 - 22

\section{ABSTRACT}

Analysis of plantar pressures during sport movement performance can provide significant information to athletes and coaches regarding sport performance and plantar loads. Tennis is a sport that is played in different surfaces. Therefore, the terrain is a critical factor that determines both the bounce of the ball, and how the player moves on the court. The purpose of this study was to examine the plantar pressures in two different surfaces of tennis courts (greenset - synthetic grass) when performing a sequence of two basic tennis movements, service and return in combination with forehand and backhand strokes.

\author{
Key words: Tennis court \\ surfaces, plantar pressures, \\ return of serve, forehand, \\ backhand \\ Received: 05 May 2016 \\ Accepted: 30 Jan 2017 \\ Corresponding author: \\ Christos Mourtzios \\ Email: \\ christosmourtzios@hotmail.gr
}

\section{INTRODUCTION}

Tennis has been called the game of quick decisions and readiness. It includes moving over very short distances and frequent changes of direction. On average 3 to 5 changes of direction are necessary at each game point and 500 during a match (Fernandez et al., 2006). Great emphasis on player development training is given to the kinetic chain. This allows force transfer from one body part to another, namely from the legs to the hips and pelvis, the shoulder and, finally, the racket (Roetert \& Kovacs, 2011).

Footwork in tennis is considered very important for the efficient movement of the player on the court. The forces on the muscles and joints of the foot can be much larger than the externally measurable ground reaction forces. Ground reaction forces increase rapidly as a result of the leg collision with the ground during running and changes in direction (Valiant and Cavanagh, 1983). These movements produce varying loads on the feet that are often underestimated.

To our knowledge, no data on plantar pressure distribution has been published for junior athletes. Therefore, plantar pressure distribution profiles for tennis-specific movements for both feet are unclear.

An important factor which affects tennis player performance is the type of tennis court surface. Two types of surface are the greenset and the synthetic grass. It is known that there are differences in tennis performance between the two specific types of surface (Miller, 2006). Previous authors have suggested that when playing on the greenest, the player movement patterns differ between grass, clay and acrylic tennis surfaces (O' Donoghue \& Ingram (2001). The purpose of this study was to examine the pressure distribution underneath both feet while performing two sequences of tennis- specific movements at two different surfaces (greenset - synthetic grass) in junior tennis players.

\section{METHODS}

\section{Subjects}

Sixteen ( 8 males, 8 females) tennis players, aged $10-16$ years (four under-10 years, four under-12 years, four under-14 years, four under-16 years, height $156.0 \pm 0.08 \mathrm{~cm}$, body mass 44.60 $\pm 8.9 \mathrm{~kg}$ ) participated in this study, boys and girls that are playing in tournaments of the Hellenic Tennis Federation.
Experimental set-up

Subjects performed randomly two different tennis-specific movements (Service and Return play) on synthetic grass and greenset.

\section{RESULTS}
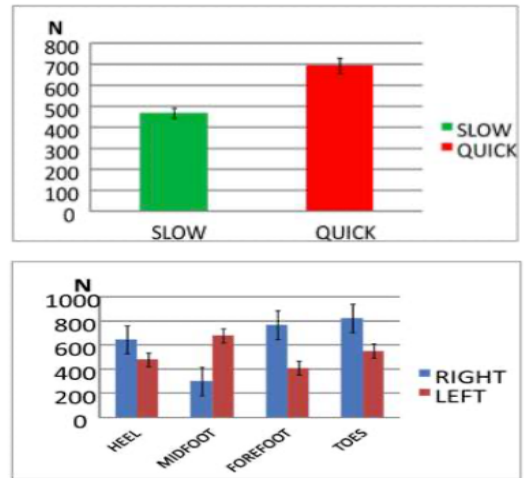

Table 1 and 2. Fmax in serve.

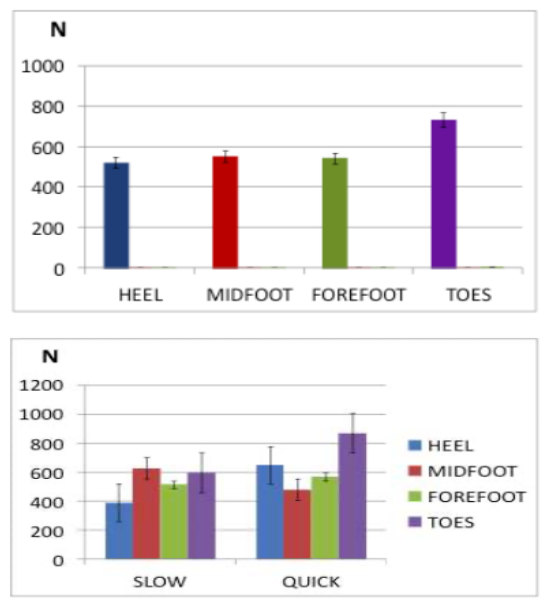

Table 2 and 3. Fmax in return. 

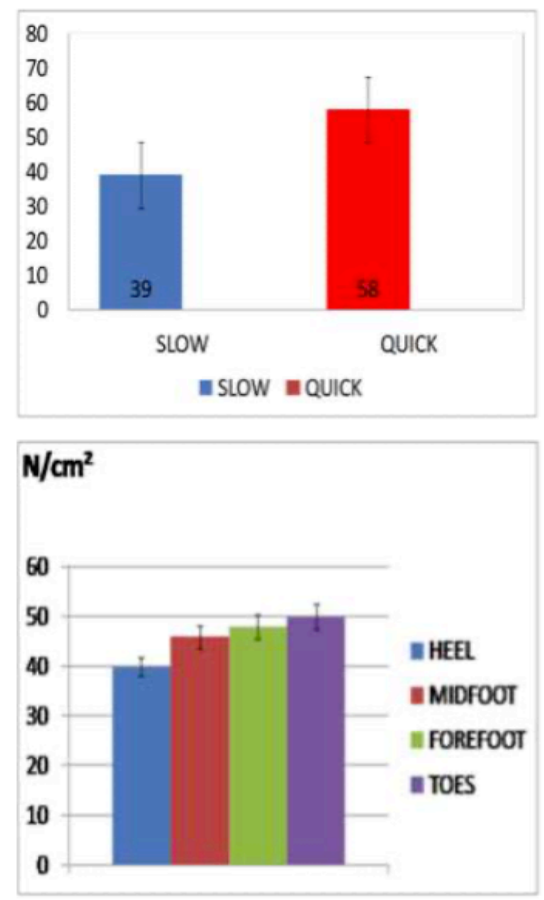

Table 5 and 6. Peak Pressure in serve.

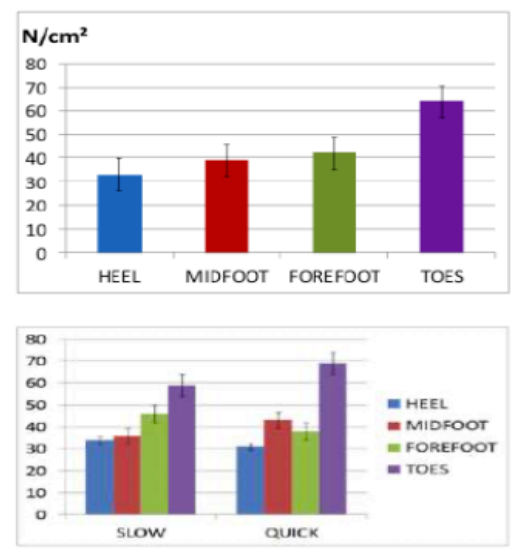

Table 7 and 8. Peak Pressure in return.

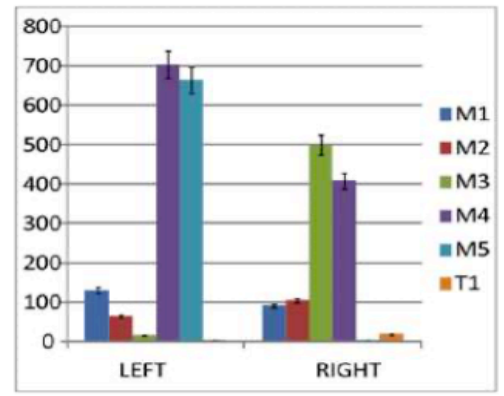

Table 9. Peak Contact Time Point in serve.

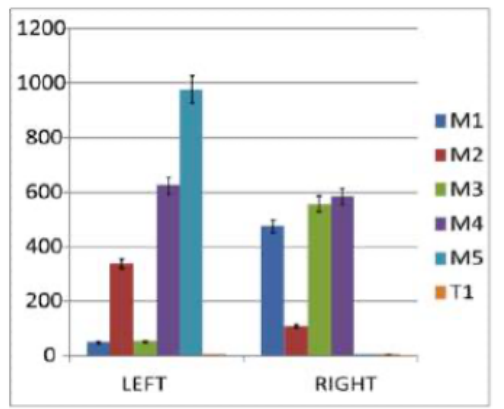

Table 10. Peak Contact Time Point in return.

\section{DISCUSSION}

The results in this study showed that the loads on the fast surface (greenset) was higher in both movements, compared to the slow surface of the synthetic grass.

The results showed that in both surfaces the loads were higher on the toes of the foot, with significant effect on the maximum pressure in the service and return of service and with significant effect on the maximum power in return.

There was no significant effect on the contact time of the two different surfaces. As measured in both the service and return movements, the contact time was longer on synthetic grass with the average contact time on the slower surface during the serve being $205 \mathrm{~ms}$ and $190 \mathrm{~ms}$ on the faster surface. For the return of serve the contact time was $202 \mathrm{~ms}$ on the slower surface and $169 \mathrm{~ms}$ on the fast. Also significant difference in contact time did not appear between left and right foot.

The average of the power was reduced on the surface of the synthetic grass against fast surface, both in the movements of service and return. This means that the risk of injury of a young athlete, because of high instantaneous vertical loads, is considerably lower at the surface of the synthetic grass. Thus, despite the fact that the fast surface imparts an advantage for a rapid movement of the athlete, the movement exhibits a higher risk. Especially in young athletes, who may not have fully developed technique and coordination skills, the choice of the synthetic grass should be preferred.

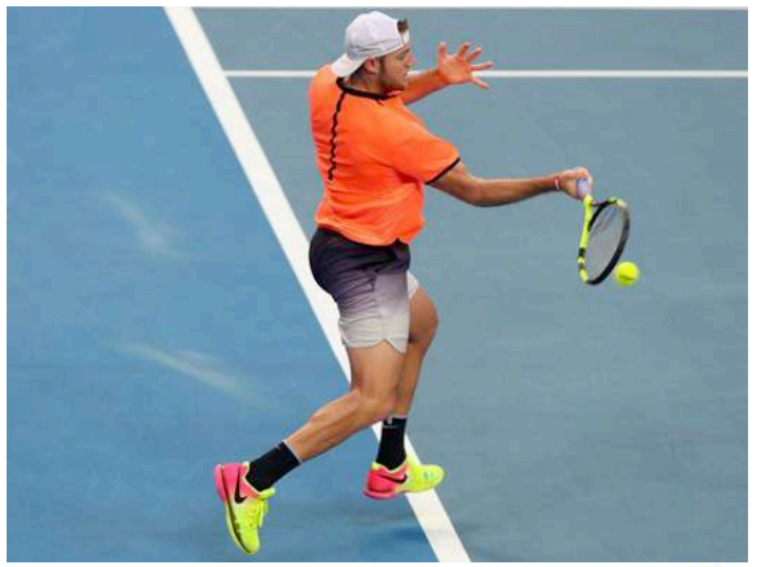

The middle of the foot had higher loadings on synthetic grass against greenset in the movement of the return of service with maximum force $629 \mathrm{~N}$ in the slow surface and $480 \mathrm{~N}$ in the fast surface. Therefore, our study for the first time shows that the differences between the two surfaces do not only concern the maximum loads but also differ in the way of loading the different regions of the foot. This has two consequences: a) that while the athlete performs the same movement sequence, the manner of execution, as it affects the plantar pressures 
differs between the two surfaces $b$ ) the various loads received on the different areas of the foot between the two surfaces suggest a different risk of injury and highlight the need to use different shoes depending on the surface on which the athlete competes.

The loads were measured and allocated to the left and right foot, with the following values. The movement of service on left foot was measured to $548 \mathrm{~N}$ in fmax and $41 \mathrm{~N} / \mathrm{cm} 2$ in $\max$ pressure, while the right foot was measured to $633 \mathrm{~N}$ in fmax and $51 \mathrm{~N} / \mathrm{Cm} 2$ in max pressure. In serve the right foot had higher loads than the left foot. In return the left measured with $594 \mathrm{~N}$ at maximum power and $40 \mathrm{~N} / \mathrm{cm} 2$ at maximum pressure, while the right to $570 \mathrm{~N}$ at maximum power and $49 \mathrm{~N} / \mathrm{cm} 2$ at maximum pressure. The results showed more maximum force produced in the left foot and the right producing more maximum pressure. Therefore, with the coach being able to know more clearly how the loads are distributed between the left and right foot, this can assist in enhancing technique, footwork and being more aware of the most efficient ways of transferring forces for more effective shot production.

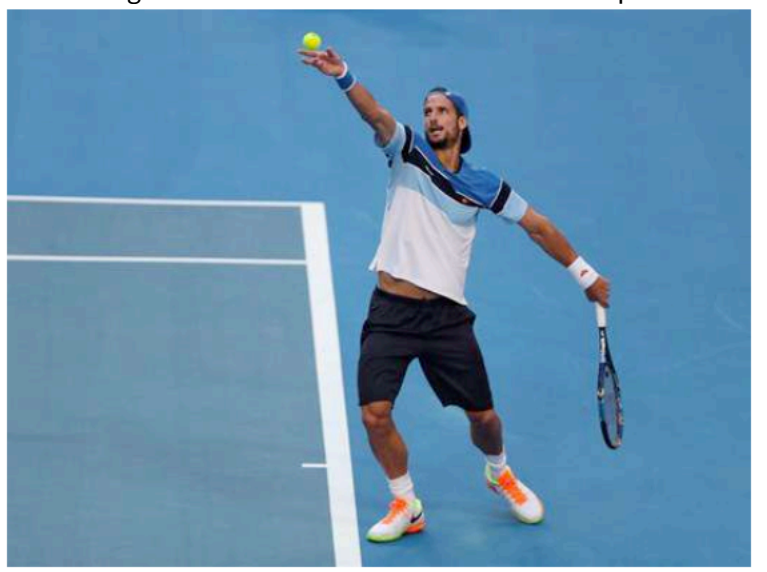

Finally the measurements of maximum load at the point of contact from the front of the right and left foot showed in service that peak loads occurred on the right foot in the third metatarsal and on the left foot in the fourth metatarsal. In the movement of the return of service the contact time point of maximum loads, appeared on the right foot in the fourth metatarsal and on the left foot in the fifth metatarsal. The conclusion we take from these measurements for the first time in our study is that the peak plantar loads are distributed to the outside side of the foot, on both feet and to both movements with the loads maximum at the beginning of the movement. Therefore, the left leg acts as a stabilizer and the right leg as a driving force for the creation of explosiveness and the transfer of forces to the execution of the strokes. In summary, by recording and analysing data coaches can use this information and apply this practically to help optimise technical execution of shots. In addition, it can be suggested that the data gained can also assist in the correct planning and content of training sessions to specifically work on the athlete effectively increasing the transfer of forces at the beginning of their service, return and groundstroke motions.

\section{PROPOSALS}

Tennis is a sport that is played on different surfaces and terrain is a critical factor determining both the bounce of the ball, and the player movements on the court. So the technique applied, mainly to the footwork, varies when tennis is played on fast or slow surfaces. The data gained from this study can assist athletes and coaches in the selection of training programs and preparing the transition from one surface to another. Research in plantar pressures may continue in-depth, because the data supplied, is very important and can help athletes of all levels, beginner- advanced, improve their skills, in cooperation with the biomechanics in order to have higher

performance, better results and fewer injuries. Data presented in this study might help shoe companies to further design tennis shoes taking into account the specific characteristics of a given playing surface. Specifically, shoes for junior tennis players should be constructed with more attention and weight to the front area of the foot, so that could help reduce impacts (shock absorption) on a particular tennis surface where excessive loading was found to be a potential danger for overloading specific areas of the foot (synthetic grass: midfoot, greenset: hallux and lesser toes areas).

\section{CONCLUSIONS}

In conclusion, the results of this investigation showed that for the athletes of young ages, it is preferable to train and play tennis in slow surfaces like synthetic grass due to lower loadings that are accepted in soles, compared with fast surfaces such as the greenset. This means fewer injuries, fewer problems in the physical development of athletes and better training.

\section{REFERENCES}

Cavanagh,PR., \& LaFortune, MA.(1980). Ground reaction forces in distance running. J Biomech,13:397406.https://doi.org/10.1016/00219290(80)90033-0

Eckl, M., Kornfeind, P. and Baca, A. (2011). A comparison of plantar pressures between two different playing surfaces in tennis. Portuguese Journal of Sport Sciences 11, Biomechanics in Sports 29.

Fernandez, J., Mendez-Villanueva, A. \& Pluim, B.M. (2006). Intensity of tennis match play. British Journal of Sports Medicine, 40(5), 387391.https://doi.org/10.1136/bjsm.2005.023168

Girard, O., Eicher, F., Fourcher, F., Micallef, J.P. \& Millet, G.P. (2007). Effects of the playing surface on plantar pressures and potential injuries in tennis. British Journal of Sports Medicine, 41, 733738.https://doi.org/10.1136/bjsm.2007.036707

Miller S. (2006). Modern tennis rackets, balls and surfaces. British Journal of Sports Medicine, 40, 401.https://doi.org/10.1136/bjsm.2005.023283

O'Donoghue, P. and Ingram, B. (2001). A notational analysis of elite tennis strategy. Journal of Sport Sciences, 19(2), 107115.https://doi.org/10.1080/0264041013000362 99

Roetert, P. Kovacs, M (2011). Tennis Anatomy. Human Kinetics Books. Valiant, GA., \& Cavanagh, PR. (1983). A study of landing from a jump: implications for the design of a basketball shoe. in,Winter DA, (ed.). Biomechanics IX, pp.117-122. Champaign, IL, HumanKinetic Publishers.

RECOMMENDED ITF TENNIS ACADEMY CONTENT (CLICK BELOW)

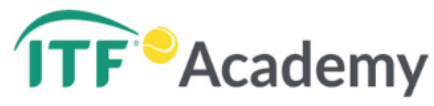

Copyright (c) Christos Mourtzios 2017 


\section{(c) (7)}

This text is under a Creative Commons BY 4.0 license

You are free to Share - copy and redistribute the material in any medium or format - and Adapt the content - remix, transform, and build upon the material for any purpose, even commercially under the following terms:
Attribution: You must give appropriate credit, provide a link to any reasonable manner, but not in any way that suggests the licensor endorses you or your use.

CCBY 4.0 license terms summary $\quad$ CCBY 4.0 license terms 